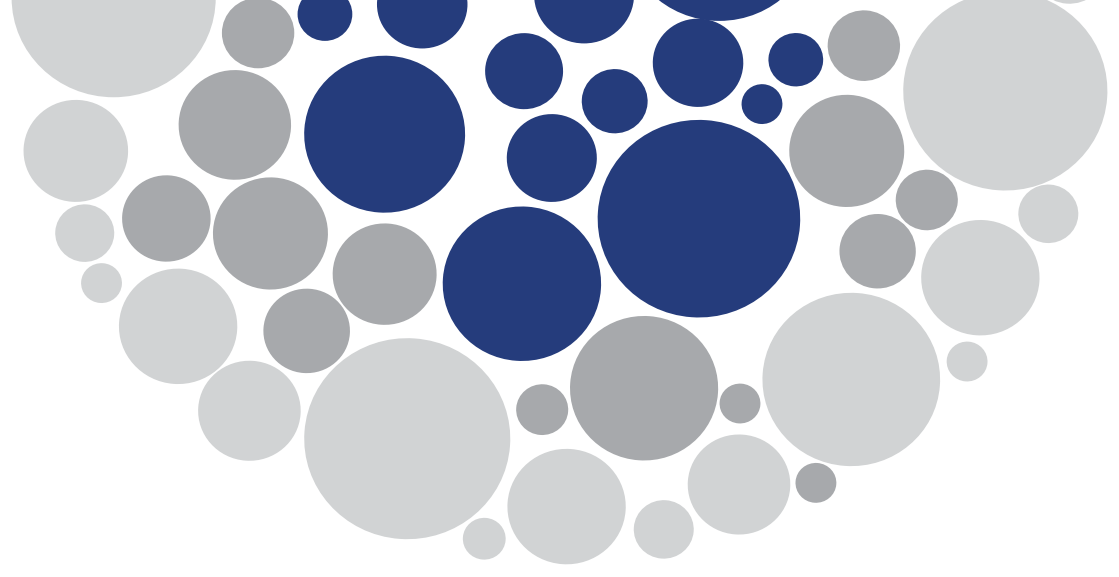

\title{
Vila da Terra: percepção após o reassentamento
}

\author{
Elaine C. R. Mendes Emerick ${ }^{a}$ Elzira Lúcia de Oliveira ${ }^{b}$ \\ a Mestranda do Programa de Mestrado em Geografia, Universidade Federal Fluminense (UFF), Campos dos Goytacazes \\ (RJ), Brasil. E-mail: elaine.emerick@gmail.com \\ • Departamento de Geografia de Campos, Universidade Federal Fluminense (UFF), Campos dos Goytacazes (RJ), Brasil. \\ E-mail: elziralucia@id.uff.br
}

\section{Introdução}

O reassentamento Vila da Terra foi construído para a realocação de famílias do $5^{\circ}$ distrito de São João da Barra, Rio de Janeiro, desapropriadas para a construção de um Distrito Industrial que compõe o Complexo Logístico Portuário, denominado Porto do Açu.

Esse reassentamento foi autorizado por meio do Decreto Estadual no $41.915 / 2009$, aprovado pela Câmara de Vereadores de São João da Barra, que permitiu a desapropriação por interesse público da área. O processo de desapropriação foi realizado pelo Governo do Estado do Rio de Janeiro, por meio da Companhia de Desenvolvimento Industrial do Estado do Rio de Janeiro (CODIN) e pela LLX, empresa de logística do Grupo EBX, posteriormente adquirida pelo grupo EIG e reestruturada atualmente como Prumo Logística (RIO DE JANEIRO, 2009).

Trata-se de uma área rural destinada, a princípio, para alocar 53 famílias consideradas elegíveis para o programa de reassentamento do empreendimento portuário. O local contou com a infraestrutura necessária para o assentamento das famílias, segundo os critérios recomendados pelo Banco Mundial. As residências foram construídas em terrenos com área mínima de 2 hectares, preparadas para o cultivo agrícola e pecuária, com solo tratado e adubado. Todas as moradias estavam equipadas com móveis e eletrodomésticos novos, além de estar em andamento um processo de formação de uma associação de moradores e produtores rurais (PORTO DO AÇU, 2017). 
O reassentamento Vila da Terra fica próximo à Rodovia BR-356, que permite fácil acesso à sede do município e a Campos dos Goytacazes, cidade de maior porte que fica perto das instalações do Porto do Açu.

O Complexo Logístico Industrial do Porto do Açu é um grande projeto industrial e de infraestrutura que produz, ao mesmo tempo, impactos positivos sobre o território e impactos negativos, especialmente, sobre os meios de vida da população diretamente impactada.

Projetos como esse também interferem na paisagem em que o ser humano já havia estabelecido suas relações e atendido às suas necessidades básicas, como moradia e subsistência. Assim, cada indivíduo desenvolve uma relação particular com o lugar, responde diferentemente diante das ações sobre o local e constrói seu julgamento com base nas experiências e expectativas próprias.

O objetivo deste trabalho é investigar a percepção das famílias sobre os impactos positivos e negativos do reassentamento a partir de vários aspectos da sua vida cotidiana. Em termos específicos, o trabalho analisa o perfil geral dos reassentados e as questões relacionadas ao uso e manejo da terra, comercialização da produção, geração de renda, relações sociais, infraestrutura da moradia, mobilidade urbana, localização geográfica e processo de negociação, em uma perspectiva comparativa da situação atual com a situação no local de origem.

A estrutura deste artigo está composta por uma fundamentação teórica com os antecedentes na literatura sobre impactos sociais causados por reassentamentos, seguida de um breve relato da área de estudo. Depois, são apresentados os materiais e métodos utilizados na pesquisa, a análise dos resultados e, por fim, as considerações finais.

\section{Antecedentes na literatura}

Segundo a definição da Organização das Nações Unidas (ONU), reassentamentos são oriundos de um deslocamento humano forçado, programados ou não planejados. São executados por órgãos públicos ou privados com base em diretrizes de organismos internacionais que atuam em defesa da justiça social e dos direitos humanos, normalmente vinculados à ONU. Os reassentados estão protegidos pelo direito à moradia, garantido pela Declaração Universal de Direitos Humanos (ORGANIZAÇÃO DAS NAÇÕES UNIDAS, 1948) e assegurado pelo artigo 6 da Constituição Federal de 1988 (BRASIL, 1988).

O deslocamento involuntário de uma comunidade torna-se relevante de ser estudado sob a ótica geográfica, pois pode impactar diretamente nas relações de um indivíduo com o espaço socialmente construído ou espaço geográfico e pode também estar edificado por diferentes escalas ou categorias, sendo que algumas delas são o território, a territorialidade, o espaço e o lugar.

O território pode ser visto sob três pontos, quais sejam: 1) como um bem jurídico-político, em que é delimitado e controlado, por meio do qual se exerce determinado poder; 2) como um bem cultural ou simbólico, sendo produto da apropriação/valorização simbólica de um grupo sobre o seu espaço; e c) como um bem econômico, na relação capital-trabalho (HAESBAERT, 2003).

O território toma então uma função de uso, aproveitamento e produção, não se restringindo ao território em si, mas entendido como um elemento de identidade, que, 
por sua vez, concebe o sentimento de pertencimento e existência. O território é a base para o trabalho, para a morada, para as trocas de saberes materiais, para o fortalecimento espiritual e para a prática de vida (SANTOS, 2006).

O território, portanto, é o que está próximo e o que conecta o ser humano ao espaço concreto, não restringindo sua dimensão, além de possuir um significado individual e social. Por isso, ele se estende até onde vai a territorialidade, a qual é aqui entendida como projeção da identidade sobre o território (MESQUITA, 1995, p. 83).

A territorialidade é complementar ao território e diz respeito à integração do indivíduo a um território quando se sente reconhecido nele, e esse sentimento produz o pertencimento a um território. A abordagem da territorialidade está direcionada ao indivíduo, em que ele é quem define a dimensão e a escala do seu espaço, suas relações, seu horizonte geográfico, suas necessidades de deslocamento e vivências. A territorialidade, nesse caso, amplifica-se nas experiências culturais, em que cada indivíduo deve ser visto, percebido e entendido (SPOSITO, 2004).

Já o espaço também é considerado lócus propulsor da produção, onde sem a produção não há lugar e sem lugar não há produção. O espaço é ainda totalizador, e cada dimensão é solidária ao todo. Nesse âmbito, a circulação, a repartição e o consumo são exercidos de forma integradora (SANTOS, 1985).

A vivência da desterritorialização e sua consecutiva reterritorialização, ou reinvenção do "novo lugar", também são explicadas por Saquet (2009, p. 216): "Na desterritorialização, perdem aspectos e elementos, relações, que tentam reproduzir no novo lugar em construção. Reterritorializam-se lentamente, reorganizando suas vidas diárias, cultural, política e economicamente no lugar", ou seja, trata-se de um processo lento de adaptação.

A luta pela terra tem mais notoriedade pela representação do Movimento dos Trabalhadores Rurais Sem Terra (MST) e do Movimento dos Atingidos por Barragens (MAB), em razão das proporções de deslocamento serem maiores. Ambos os casos estão associados aos processos de territorialização de indivíduos submetidos a um processo de desterritorialização e reterritorialização. Considerando o deslocamento provocado por empreendimento portuários, as comunidades deslocadas têm como futuro a reconquista do novo território e do seu modo de viver (MEDEIROS; LINDER, 2014).

$\mathrm{Na}$ ausência de legislação específica, os responsáveis por projetos de reassentamento valem-se, geralmente, das diretrizes estabelecidas pelo Banco Mundial - primeira instituição financeira internacional a desenvolver uma salvaguarda sobre reassentamento involuntário -, que depois serviram como modelo para outras instituições. Logo, a lacuna na legislação não é exclusividade do Brasil (FUNDAÇÃO RENOVA, 2018).

Os elementos mínimos da Política Operacional de Reassentamento são compostos por: levantamento censitário das pessoas deslocadas; avaliação dos bens; descrição de compensação e outras assistências ao reassentamento a serem fornecidas; consultas à população deslocada acerca de alternativas aceitáveis; responsabilidade institucional pela implementação; procedimentos para a apresentação e resolução de reclamações; acordos para monitoramento e implementação; cronograma e orçamento (CORPORAÇÃO FINANCEIRA INTERNACIONAL, 2012).

No plano internacional, destacam-se os trabalhos de Tan e Yao (2006) e Wilmsen, Webber e Duan (2011), que abordaram questões de reassentamentos resultantes da construção da Usina Hidrelétrica de Três Gargantas, na China. Esses autores examinaram os problemas ambientais críticos associados ao reassentamento do projeto, revelando o 
impacto ambiental resultante de uma contradição entre a área inundada e a demanda de terras para o reassentamento, mas também apresentaram ações de contramedidas positivas, como obras de engenharia para proteção de terras agrícolas, desenvolvimento de ecoagricultura e ajustes na política de reassentamento (TAN; YAO, 2006).

Estudos que relatam diversos pontos de impactos sociais pós-reassentamento, relacionados às comunidades estudadas, poderão ser vistos nos parágrafos subsequentes, atrelados à análise da percepção dos moradores do reassentamento Vila da Terra.

No trabalho de Scott (2006), processos de adoecimento, sofrimento e administração de saúde, como fases dos impactos sociais de grandes projetos em desenvolvimento, foram resultantes do reassentamento realizado para a construção da Usina de Itaparica pela Companhia Hidroelétrica do São Francisco (CHESF), próximo à cidade de Petrolândia, no estado de Pernambuco, hoje conhecida como Usina Luiz Gonzaga.

Já o declínio na geração de renda foi um ponto estudado por Wilmsen, Webber e Duan, (2011), que relataram os efeitos do reassentamento de lares agrícolas de duas aldeias dentro da área inundada pela barragem da hidroelétrica chinesa, propondo um quadro político-econômico para entender o programa de reassentamento e suas implicações para as famílias. Como resultados, esses autores encontraram evidências de que os rendimentos agrícolas das famílias diminuíram, não sendo compensadas pelo aumento dos rendimentos adicionais de trabalhos remunerados propostos, tampouco pelos trabalhos autônomos, o que tornou as famílias mais vulneráveis a novos choques externos do que antes do reassentamento.

Por sua vez, discordâncias no processo de legalização do reassentamento foi um fator que surgiu no estado de Tocantins, na Usina Hidrelétrica de Luís Eduardo, onde o processo de negociação da transição para o reassentamento de Magalhães apresentou tensão. Houve forças de resistência, insegurança da população e sentimento de exclusão por causa da não participação coletiva dos reassentados nas etapas precedentes à implantação dos projetos de reassentamento (PARENTE, 2015).

O mesmo aconteceu com os indivíduos que formam o Movimento dos Atingidos por Barragens (MAB), desapropriados em função da construção da Barragem de Dona Francisca, no estado do Rio Grande do Sul, relatado em Mera et al. (2018), e com a Comunidade Rural de São Sebastião do Soberbo, atingida pela construção da Usina Hidrelétrica Risoleta Neves, em Minas Gerais, apresentada na pesquisa de Fonseca et al. (2015). Entre as diversas insatisfações, a questão judicial foi a mais evidente (MERA et al., 2018).

Em contrapartida, a pacificação no processo judicial compõe a análise realizada com a Comissão Regional dos Atingidos por Barragens do Rio Iguaçu (CRABI), no assentamento dos ribeirinhos atingidos pela construção da Hidrelétrica de Salto Caxias, no estado do Paraná, conforme Derrosso e Ichikawa (2013). Nesse estudo, foram detectadas unicidade e organização da população e sinergia entre a empresa e a participação da população na CRABI, movimento social que procurou ser um interlocutor da população ribeirinha com as forças do estado.

Alguns estudos associam o novo local a um processo de isolamento social, alegando que a população dedica muito tempo para o trabalho e pouco tempo para a convivência social em comunidade. É o caso do reassentamento coletivo Nova Mutum Paraná, oriundo da antiga vila de Mutum-Paraná, em Rondônia, cujos indivíduos se ressentiam quanto à diferença na paisagem natural, como existência de poucas árvores e ausência de sombra 
nos quintais. O deslocamento rompeu com as fortes relações dos moradores com o local de origem, a sensação de pertencimento ao lugar, a harmonia com a paisagem natural como fonte de lazer para realizar caçadas nas matas da região, pescar nos rios, banhar-se nos riachos, jogar futebol e frequentar a igreja (RIBEIRO; ANDRADE; MORET, 2015).

Vantagens na qualidade de vida também são apontadas nos estudos consultados, como no caso dos agricultores organizados pelo MAB da Barragem de Dona Francisca, no estado do Rio Grande do Sul (MERA et al., 2018), e dos moradores do reassentamento Mariana, oriundos da Usina Hidrelétrica Luís Eduardo Magalhães, no estado do Tocantins (SANTOS; SOUZA; PREVIERO, 2016). Neste último, as vantagens geradas na manutenção e no adensamento da vegetação nos quintais ao longo dos anos no reassentamento são reflexos dos elementos sociais e culturais, que representam a sensibilidade ambiental dos moradores e mantenedores desse espaço. Os moradores relataram também outros benefícios associados aos quintais agroflorestais, tais como: qualidade de vida proporcionada pelo sombreamento das residências e espaço usado como área de lazer entre as famílias, tanto para eventos de datas comemorativas como para reunião no horário do almoço e no final da tarde (SANTOS; SOUZA; PREVIERO, 2016).

Outro aspecto muito relevante são as relações de uso, manejo e produção da terra. Como as comunidades reassentadas são majoritariamente agrícolas, esse fato se torna crucial para a continuidade desse saber, passado, muitas vezes, de geração para geração. No reassentamento coletivo Nova Mutum Paraná (RIBEIRO; ANDRADE; MORET, 2015), no reassentamento da Usina Hidrelétrica de Luís Eduardo Magalhães (PARENTE, 2015) e no coletivo de agricultores organizados pelo MAB da Barragem de Dona Francisca (MERA et al., 2018), as novas formas de produzir e comercializar alteraram a dinâmica diária das famílias. Esses mesmos autores registraram também a percepção das comunidades quanto às mudanças das relações sociais com a vizinhança, em que prevaleceram a amizade e a dinâmica de compadrio, incluindo ajuda mútua em épocas de colheita e no cuidado com as crianças.

Dificuldades de adaptação ao novo relevo e paisagem para continuidade dos saberes agrícolas também foram considerados impactos por Roquetti et al. (2017), no caso da construção da Usina Hidrelétrica de Barra Grande, que retirou os agricultores das encostas íngremes do rio Pelotas para colocá-los nas áreas planas dos municípios afetados. Além disso, a criação do reservatório de água também diminuiu a oferta de áreas produtivas nas encostas do rio. Esse deslocamento forçou os produtores rurais a lidar com novas condições ecológicas para dar continuidade a seus modos de vida e produção. Fatores como declividade, acidez do solo, fertilidade, umidade e microclima diferem significativamente nas encostas e nos campos, além do aumento do preço da terra nas áreas planas em razão da especulação da compensação financeira oferecida para quem não quis ir para reassentamento rural coletivo.

Por outro lado, houve resultados positivos quanto à adaptação aos novos modos de produção no reassentamento dos ribeirinhos atingidos pela construção da Usina Hidrelétrica de Salto Caxias, no estado do Paraná, pelo fato de ter ocorrido um aprendizado dos ribeirinhos que seriam deslocados, em razão da construção de outras hidrelétricas na região, e por terem se mobilizado em tempo para evitar maiores perdas, ou seja, os movimentos sociais, com ação coletiva, ajudaram no reforço de uma identidade social, em que os sujeitos envolvidos passaram a partilhar de uma identidade coletiva e positiva da situação (DERROSSO; ICHIKAWA, 2013). 
Já o aumento da produção foi um indicador na percepção dos moradores do reassentamento Mariana, oriundos da Usina Hidrelétrica Luís Eduardo Magalhães, pois as mudanças das espécies outrora plantadas e as comercializações tanto dos frutos quanto das polpas aumentaram no reassentamento. Os proprietários dos quintais agroflorestais começaram a ser beneficiados com o retorno financeiro, dessa forma eles passaram a investir de forma sustentável na manutenção e diversificação das espécies nativas ou exóticas (SANTOS; SOUZA; PREVIERO, 2016).

A infraestrutura física também foi um atributo considerado no reassentamento da Usina Hidrelétrica de Luís Eduardo Magalhães (PARENTE, 2015) e na Comunidade Rural de São Sebastião do Soberbo, atingida pela Usina Hidrelétrica Risoleta Neves (FONSECA et al., 2015). Nas entrevistas de Parente (2015), a comunidade relatou que o tamanho dos lotes rurais era incompatível com a necessidade produtiva das famílias. Já no estudo de Fonseca et al. (2015), os entrevistados indicaram que as casas do reassentamento eram superiores as de outrora $-65 \%$ dos entrevistados alegaram a melhora nas moradias -, além do fato de terem as ruas asfaltadas.

A localização geográfica em relação aos centros comerciais mais próximos foi uma questão abordada por Ribeiro, Andrade e Moret (2015) em Nova Mutum Paraná. Em Mera et al. (2018), os agricultores organizados pelo MAB da Barragem de Dona Francisca, no estado do Rio Grande do Sul, sentiam-se em isolamento por não haver comércio, pelo fato de o transporte público ocorrer somente três vezes por semana e pelas estradas precárias, até mesmo para carros pequenos, o que acarretava constantes manutenções, onerando as famílias e dificultando o acesso aos serviços de saúde, educação e trabalho.

A fim de ter mais assertividade para escolha de uma área destinada ao reassentamento, Scott (2006) aplicou uma metodologia de análise multicritério (Analytic Hierarchy Process - AHP), levando em consideração os critérios de topografia das áreas, aptidão para cultivos diversos, possibilidade de ocupação humana, distância da bacia do rio São Francisco e restrições legais. Já Vilela et al. (2017) classificaram 10 hectares distribuídos em 290 áreas que seriam ideais para a criação de reassentamentos rurais provenientes das desapropriações do projeto de Integração do Rio São Francisco, mais especificamente no Ramal Agreste, nos municípios de Sertânia e Arcoverde, no estado da Paraíba, porém, neste caso, não houve uma avaliação da percepção dos reassentados após essa definição.

No âmbito geral, o processo de adaptação apresenta dificuldades no novo território, principalmente nas memórias afetivas. No estudo realizado com reassentados de barragens no Rio Grande do Sul, os entrevistados diziam que: "sempre quando a gente vai falar, dá uma saudade imensa, porque era muito diferente" (MEDEIROS; LINDER, 2014, p. 270).

Observa-se na literatura disponível sobre reassentamentos que a maior parte dos estudos sobre reassentados se refere ao deslocamento por barragens de hidrelétricas, especialmente no caso do Brasil, dado o vasto número de construções dessa natureza. Logo, analisar esse aspecto tendo um complexo portuário como fonte de impacto torna-se muito significativo, uma vez que existem poucas referências a esse respeito.

O Relatório de Impacto Ambiental de 2006, no levantamento dos impactos no meio social, realizou estudos sobre a organização e a dinâmica territorial com base na sua lógica de organização, auxiliando na avaliação da interferência do empreendimento sobre os padrões de assentamento e mobilidade da população local e as bases econômicas local 
e regional. De acordo com o relatório, na área de influência direta do empreendimento, existiam vínculos de dependência dos recursos naturais terrestres e marinhos. Esses vínculos tinham como centralidade as atividades de pesca, pequena agricultura de subsistência e ocupação para segunda residência de veraneio para o perfil de classe média (MMX, 2006).

A percepção dos futuros impactos sociais foi identificada por meio de pesquisa realizada com os pescadores, que relataram receio que o empreendimento reduzisse ainda mais o campo de pesca, pois ali estavam localizados seus principais pesqueiros. Em contrapartida, reivindicavam o reconhecimento de sua situação, uma política de atendimento a seus interesses e a busca de alternativas para o desempenho de sua atividade. Os moradores litorâneos demonstraram temor que a área se transformasse em um espaço industrial e que, com isso, tivessem de abandonar sua vocação turística, o que penalizaria aqueles que viviam da prestação de pequenos serviços associados à atividade turística e de veraneio. Já os ocupantes da Fazenda Saco Dantas relataram o receio de terem que desocupar a área sem uma alternativa para o plantio, perdendo as benfeitorias realizadas nos lotes, e renunciar a colheita. Ainda, as comunidades interioranas manifestaram insegurança com a construção do porto por causa do crescimento do fluxo de veículos, com prejuízo para configuração espacial e social em que viviam, e enfatizaram também a inexistência de asfaltamento na maioria das comunidades. O receio pela chegada de pessoas de outras regiões, o que poderia prejudicar e interferir no cotidiano dessas populações locais, também foi apontado (MMX, 2006).

As expectativas da população em geral quanto ao Complexo Industrial do Porto do Açu foram registradas por Piquet e Shimoda (2014), que pesquisaram a percepção das populações dos municípios de São João da Barra e Campos dos Goytacazes quanto aos impactos econômicos e à oferta de serviços que o empreendimento portuário provocaria localmente. A pesquisa de campo considerou os itens emprego, segurança, trânsito, educação, saúde, comércio, meio ambiente, preço de produtos e serviços, agricultura, água e saneamento. Como resultado, mais de $50 \%$ da população de São João da Barra considerou que a instalação iria melhorar muito os aspectos da empregabilidade, o setor de educação, o comércio, a distribuição de energia, as condições gerais do abastecimento de água e saneamento básico (PIQUET; SHIMODA, 2014).

Da mesma forma, Lopes et al. (2011) indicaram que 70\% da população tinha expectativa de desenvolvimento da região e considerava o empreendimento portuário como muito bom e que $90 \%$ dos pesquisados reportaram que estavam esperançosos em melhorar sua condição de vida em função do empreendimento.

Em contraponto, forças de resistências foram apresentadas por parte da população rural diretamente atingida, provenientes do $5^{\circ}$ distrito de São João da Barra. Essas comunidades, segundo estudos, tinham como principais atividades a pesca, a criação de animais (suínos, aves e bovinos) e a administração de pequenos estabelecimentos comerciais. Os motivos de resistências estavam atrelados à desconsideração ao sentimento de pertencimento em relação ao território em que viviam, exclusão de todo o processo decisório e fragmentação do processo de desapropriação, onde novas áreas eram anexadas ao projeto do complexo, instaurando na população tensão e incertezas. Então a Associação de Proprietários Rurais e de Imóveis do Município de São João da Barra (ASPRIM) foi criada como interlocutora da população com a empresa (PRADO; ROCHA, 2015). 


\section{3. Área de estudo}

O reassentamento Vila da Terra localiza-se em São João da Barra, município que possui uma área total de $452,894 \mathrm{~km}^{2}$, correspondentes a 4,7\% da área do Norte Fluminense, e uma população estimada, em 2019, de 36.102 habitantes, equivalente a 3,9\% do contingente dessa região.

O município tem como principais atividades econômicas o turismo, agropecuária, olericultura, fruticultura ativa, artesanato e pesca. Entretanto, a maior parte das receitas municipais está concentrada nos royalties e no recolhimento do Imposto Sobre Serviços (ISS) (RIO DE JANEIRO, 2019). Na Figura 1, é apresentada a evolução da arrecadação de ISS e royalties no município, em que se observa que, em 2001, a arrecadação de ISS representava menos de R $\$ 1$ milhão, correspondendo a cerca de 3\% das receitas do município, enquanto, em 2017, já representava $16,8 \%$ das receitas municipais (RIO DE JANEIRO, 2019). O crescimento do ISS indica uma fonte de receita que reduz a dependência do município dos royalties, os quais representam valores expressivos, mas apresentam grande volatilidade.

A Vila da Terra foi construída na Fazenda Palacete, em São João da Barra, como uma das ações propostas no reassentamento das famílias, sendo destinada uma área mínima de 2 hectares para cada reassentado, e em cada propriedade foi construída uma casa com medidas entre 68 e $109 \mathrm{~m}^{2}$, com dois, três ou até quatro quartos. Todas as 53 residências possuíam máquina de lavar, televisor, geladeira, fogão e computador, além dos móveis de sala e de quarto e armários de cozinha.

$\mathrm{O}$ reassentamento fica próximo à Rodovia BR-356 e à Rodovia RJ-240, que são vias que dão acesso aos municípios de São João da Barra e Campos dos Goytacazes e ao

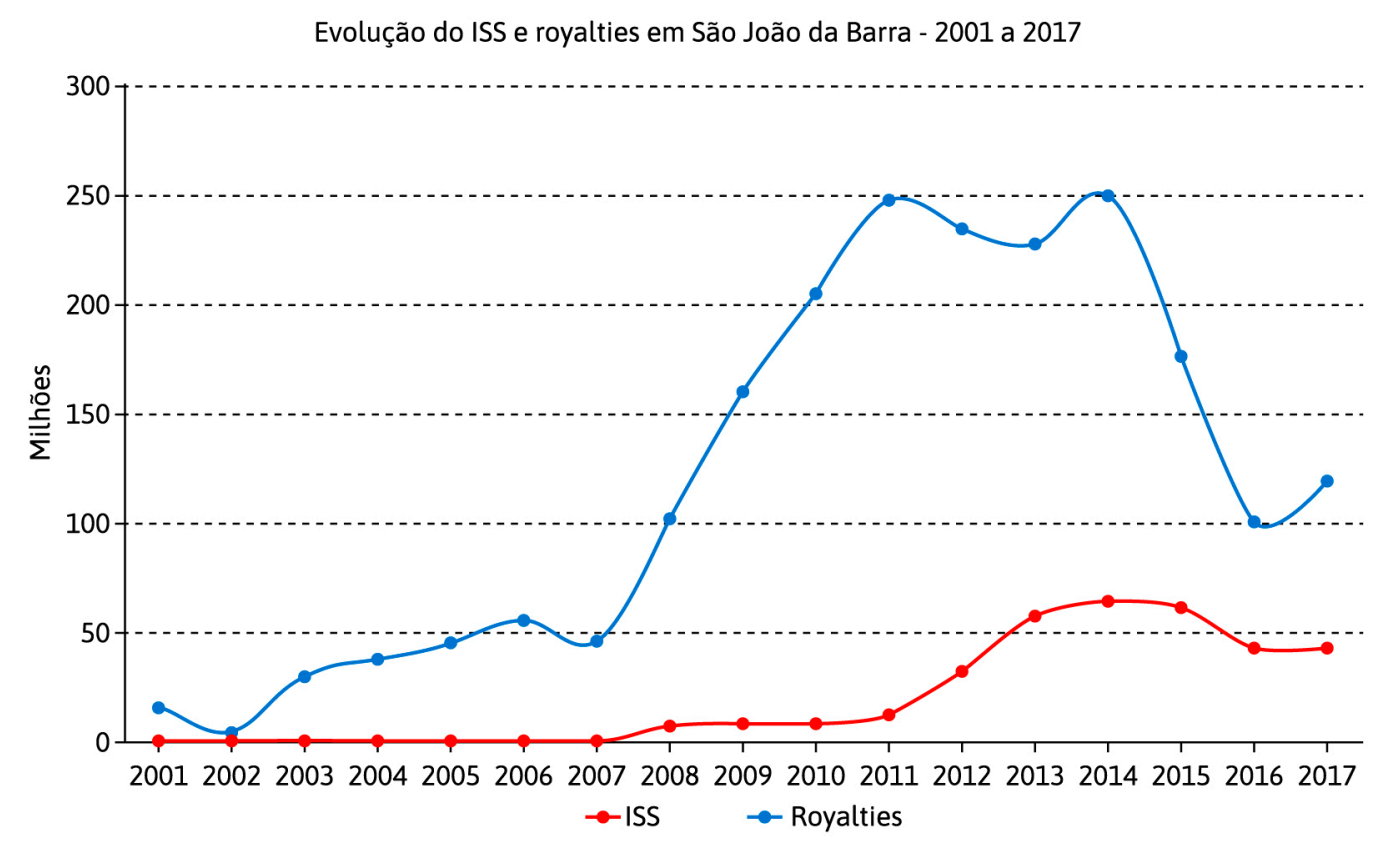

Figura 1 - Evolução do ISS e royalties de 2001 a 2017 em São João da Barra.

Fonte: elaborada pelas autoras com base em Rio de Janeiro (2019). 
Porto do Açu, respectivamente. A localidade faz parte da área de influência direta do empreendimento portuário. A Figura 2 apresenta um cartograma com a localização da Vila da Terra e seu posicionamento geográfico em relação ao Porto do Açu e à sede de São João da Barra.

\section{Materiais e Métodos}

Para identificar a percepção de reassentados em relação às alterações provocadas nos diversos aspectos da sua vida, foi realizado um levantamento censitário por meio de um questionário estruturado. A pesquisa foi aprovada pelo Comitê de Ética das Ciências Humanas e Sociais Aplicadas, e cada entrevistado assinou o Termo de Consentimento Livre e Esclarecido. É importante salientar que a aplicação do questionário não ofereceu nenhum risco físico ou constrangimento aos participantes. Ainda, se algum entrevistado

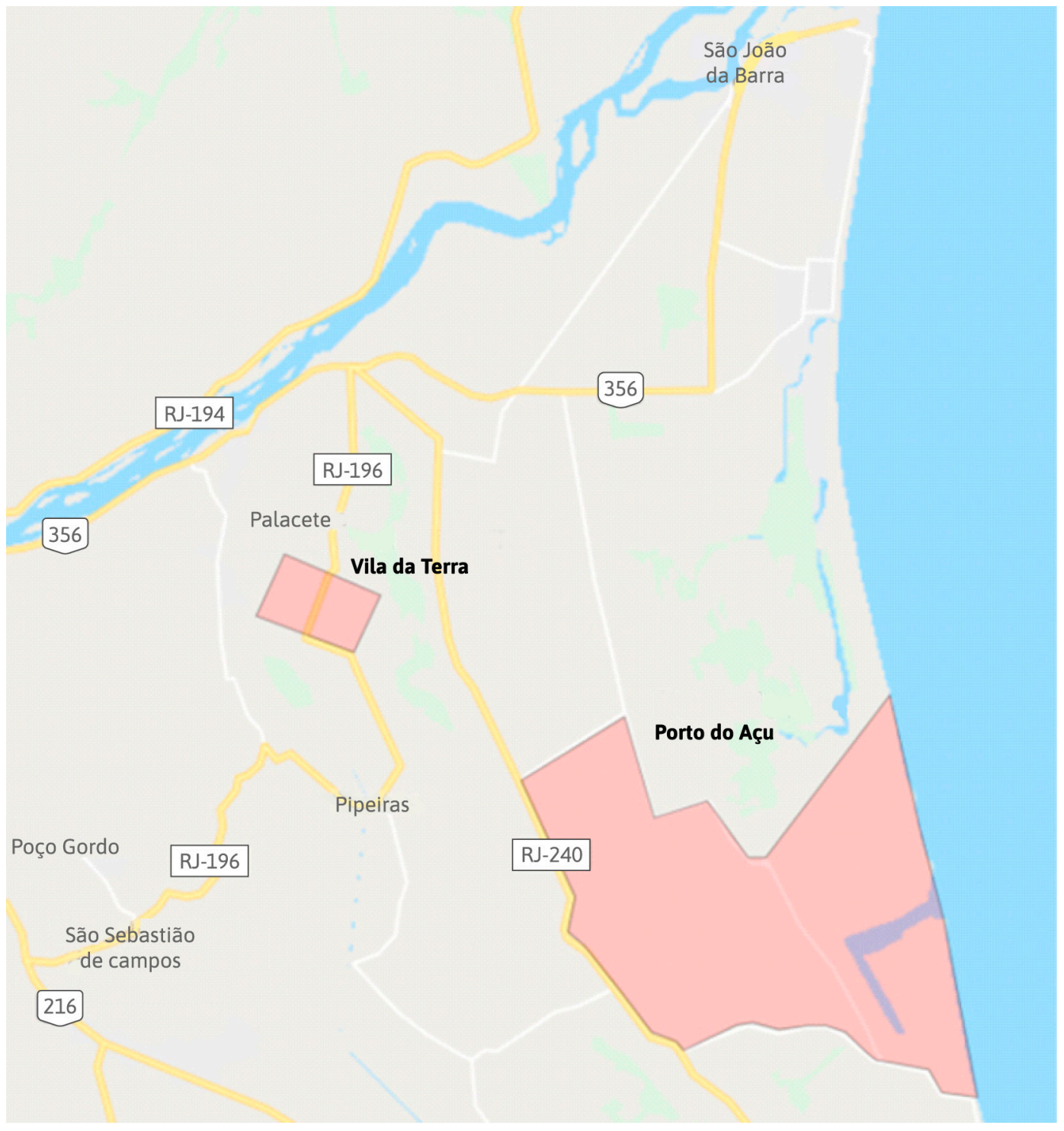

Figura 2 - Localização da Vila da Terra.

Fonte: adaptada pelas autoras a partir do Google Maps. 
se sentisse desconfortável em responder a alguma questão, o quesito não era respondido ou o questionário era interrompido.

O questionário foi estruturado em três blocos: bloco A - dados de identificação e caracterização dos indivíduos; bloco B - investigação da vida no local de origem; bloco C - investigação da vida na Vila da Terra. Os atributos considerados para análise comparativa estarão relacionados ao perfil geral dos entrevistados, uso e manejo da terra, comercialização da produção, relações sociais, infraestrutura da moradia, localização geográfica, mobilidade urbana e lazer, e processo de negociação. Também foram feitas questões abertas quanto à moradia anterior e à atual, para que o entrevistado ficasse à vontade para se expressar.

Após a coleta e análise crítica, os dados foram processados e tabulados por meio do software IBM SPSS Statistics, sendo realizada uma análise descritiva dos dados.

\section{Resultados}

Foram realizadas 40 entrevistas, das quais 30 se referiram a assentados originais e 10 não foram elegíveis, pois eram compostas por novos moradores que compraram terrenos de reassentados (3 casos), ocupavam casas cedidas ( 2 casos) ou residiam de aluguel no reassentamento (5 casos). Em maioria, $40 \%$ (16) das famílias viviam no $5^{\circ}$ Distrito de São João da Barra, e 35\% (14), na antiga Fazenda Saco Dantas, áreas desocupadas para implantação do Porto do Açu.

Considerando os 30 reassentados elegíveis, identificou-se que 53\% eram homens e $47 \%$ eram mulheres. A maior parte tinha idade entre 29 e 69 anos, sendo que $40 \%$ possuíam de 29 a 49 anos; 47\%, entre 50 e 69 anos; e 13\%, 70 anos ou mais. A escolaridade em geral era baixa, já que $43 \%$ deles declararam que não sabiam ler e escrever; $43 \%$ não completaram o ensino fundamental; $7 \%$ possuíam o ensino fundamental completo; $3 \%$ completaram o ensino médio; e 3\% tinham ensino superior. Os casados e em união estável somavam 77\%; os solteiros, $13 \%$; os viúvos, 7\%; declararam outras situações, $3 \%$. Quanto ao tamanho dos domicílios, verificou-se que $13 \%$ eram unipessoais; $33 \%$, compostos por duas pessoas; e $40 \%$, por três pessoas.

A atividade de agricultor era exercida com exclusividade por $43 \%$ dos chefes de família; de comerciante, por $10 \%$; de pesca, $3 \%$. Além disso, $3 \%$ eram aposentados. O tempo de moradia na Vila da Terra variava de 4 a 9 anos, sendo que $40 \%$ viviam no local há 7 anos; $20 \%$, há 8 anos; e $7 \%$, há 9 anos.

Em convergência com os trabalhos de Parente (2015) e Fonseca et al. (2015), a infraestrutura física comparativamente ao local de origem foi percebida pelos reassentados como melhor, com ênfase para: quantidade de dormitórios, os quais, em 29 casas, eram iguais ou superiores à da casa original; terreno independente para 12 famílias que moravam anteriormente em terrenos compartilhados com outros membros do grupo familiar; piso em cerâmica; acesso a redes de telefonia móvel; eletrodomésticos e móveis novos. Foram apontados como positivos também o material construtivo da cobertura da residência, composta por laje junto ao telhado de cerâmica, e as vias pavimentadas com acesso mais próximo aos centros de São João da Barra e Campos dos Goytacazes.

Quanto ao uso e manejo da terra, a classificação da fertilidade da terra revelou que 17 famílias (56,7\%) apontaram a terra da moradia anterior como fértil, sendo que, na Vila 
da Terra, 24 famílias (80\%) indicaram essa classificação. Esse aumento teve contribuição de famílias que consideravam a terra anterior pouco fértil (no caso, 7 famílias, ou 23,3\%) e que, em sua percepção, a terra disponibilizada passou a ser classificada como fértil. Das espécies mais vendidas na localidade anterior, destacavam-se o quiabo (relatado por 11 famílias), o maxixe (10 famílias) e a mandioca, ou aipim (3 famílias). Em contrapartida, na Vila da Terra, a mandioca foi reportada como a cultura mais vendida (14 famílias), seguida pelo quiabo ( 7 famílias) e pelo maxixe ( 5 famílias). Em que pese à menor criação de animais na Vila da Terra, em contrapartida os assentados contavam com acesso gratuito à assistência técnica e maquinário para uso e manejo na terra, o que não dispunham na localidade anterior.

Esses resultados apresentam aderência com o trabalho de Santos, Souza e Previero (2016), que relataram percepção de melhora na produção agrícola pelos moradores do reassentamento Mariana, oriundos da Usina Hidrelétrica Luís Eduardo Magalhães, pois as mudanças das espécies outrora plantadas e as comercializações tanto dos frutos quanto das polpas aumentaram no reassentamento. Da mesma forma, Derrosso e Ichikawa (2013) relataram experiências positivas percebidas pelos atingidos em razão da construção da Usina Hidrelétrica de Salto Caxias, no estado do Paraná.

A localização geográfica em relação aos centros comerciais mais próximos foi uma questão abordada por Ribeiro, Andrade e Moret (2015) e por Mera et al. (2018). Para os reassentados da Vila da Terra, esse atributo apresentou ganhos, uma vez que eles se localizavam mais próximos aos centros de São João da Barra e Campos dos Goytacazes, possuíam vias asfaltadas e transporte público passando em frente às residências e gratuito para São João da Barra.

A questão de capital social foi valorizada pelos reassentados, que, em geral não consideraram que houve prejuízo nas relações sociais com a mudança: 22 apontaram o relacionamento com os vizinhos da comunidade anterior como "Bom" e mantiveram essa indicação na Vila da Terra; 2 transitaram de "Bom" na residência anterior para "Ótimo" na Vila da Terra; 2 passaram de "Regular" no local de origem para "Ótimo" e "Bom" na Vila da Terra. Em contrapartida, 4 entrevistados relataram que deixaram de se socializar, assim como 6 deixaram de ter sensação de segurança na Vila da Terra. Isso se deve, provavelmente, ao número de roubos de que tiveram conhecimento no novo espaço, em relação à residência anterior (7 na residência anterior e 29 na Vila da Terra).

A relação com o lugar anterior foi fortemente relacionada com a paisagem e os laços afetivos, já que os recursos naturais foram reportados por 15 reassentados, e os laços afetivos, por 21.

Os pontos positivos, relatados de forma livre pelos reassentados, quando perguntados sobre o que mais gostavam na Vila da Terra, foram agrupados pelos atributos de localização, infraestrutura, ambiental, social e financeiro. A localização foi um ponto recorrente, por se situar mais próximo aos centros de São João da Barra e Campos dos Goytacazes, relatado por 18 pessoas; na sequência, vieram a fertilidade da terra (8 pessoas), a casa nova ( 7 pessoas) e a tranquilidade do local (5 pessoas).

A média de renda familiar apresentou um aumento de $186 \%$, passando de $\mathrm{R} \$ 697,00$ para $\mathrm{R} \$ 1.997,00$. Acrescenta-se ainda que $75 \%$ das famílias que recebiam uma renda familiar de até $\mathrm{R} \$ 1.000,00$ na residência anterior passaram a receber, na Vila da Terra, uma renda familiar de até $\mathrm{R} \$ 2.400,00$. A renda média mensal oriunda dos bens da terra, comparada à vida anterior ao reassentamento, apresentou melhora, sendo o aumento 
da renda média de $\mathrm{R} \$ 513,33$ para $\mathrm{R} \$ 643,00$, o que representou 125\% de acréscimo, e $75 \%$ das pessoas que recebiam renda de até $R \$ 800,00$ na residência anterior passaram a receber R \$1.100,00 na Vila da Terra. Esses resultados divergem do trabalho de Wilmsen, Webber e Duan (2011), que avaliaram os efeitos do reassentamento de lares agrícolas de duas aldeias dentro da área inundada pela barragem da hidroelétrica chinesa. Como resultados, esses autores encontraram evidências de que os rendimentos agrícolas das famílias diminuíram, não sendo compensados pelo aumento dos rendimentos adicionais de trabalhos remunerados propostos ou trabalhos autônomos, o que tornou as famílias mais vulneráveis a novos choques externos do que antes do reassentamento.

O sentimento de tristeza no dia da mudança foi relatado por 14 (46,7\%) entrevistados. Em contrapartida, 8 (26,7\%) disseram se sentir felizes com a mudança, 7 (23,3\%) se mostraram indiferentes e $1(3,3 \%)$ não soube responder. Relatos de adoecimento e sofrimento não foram detectados, como exposto em outros reassentamentos estudados, como no caso da construção da Usina de Itaparica pela CHESF, próximo à cidade de Petrolândia, no estado de Pernambuco, hoje conhecida como Usina Luiz Gonzaga (SCOTT, 2006). Tal fato pode ser ancorado quando se compara a vida na casa anterior ao reassentamento com a vida na Vila da Terra.

\section{Considerações finais}

Pode-se observar, por meio deste estudo, a importância da busca em perceber, pesquisar e registrar o sentimento das famílias reassentadas, tendo em vista os vários impactos ocorridos na vida das 30 famílias entrevistadas, considerando que algumas já estavam reassentadas há quase 9 anos.

Como visto, os impactos dos atributos pesquisados, em linhas gerais, são expostos pelos reassentados como pontos de melhora, principalmente nos tópicos relacionados à nova localização, fertilidade da terra e posse individual para aqueles que compartilhavam suas casas em terrenos cedidos. Ainda, pode-se observar pelo tempo de permanência no reassentamento que a maioria das famílias se adaptou ao plantio, tendo essa prática inclusive crescido. No quesito emocional, fica clara a tristeza no dia da mudança, pois o vínculo com casa original construída pela maioria das famílias, o apreço ao local de origem, as memórias e a saudade são sentimentos que irão perdurar. Além disso, pode-se elencar a queda no sentimento de segurança e no hábito de socializar, atributos emocionais desafiadores para serem reconstruídos.

Não cabe a este texto julgar que os ganhos físicos e materiais se sobrepõem aos emocionais, mas os atributos de satisfação dos reassentados quanto à nova vida, no comparativo entre a casa anterior e a Vila da Terra, permitem afirmar que as suas vidas mudaram para melhor. Esse resultado é raramente encontrado quando se trata de reassentamentos compulsórios, como os casos de estudos tomados como base neste trabalho, nos quais a maioria apresentou insatisfações e dificuldades por parte dos reassentados.

O registro da percepção das famílias reassentadas torna-se de extrema importância para a contribuição e o acúmulo de conhecimento para futuros deslocamentos compulsórios, até mesmo para subsidiar o escopo de uma legislação que possa vir a ser proposta no âmbito governamental. As comunidades não devem ficar sem ouvidoria em sua nova 
vida, sendo os estudos acadêmicos uma ferramenta que pode e deve ser usada para preencher essa lacuna na legislação.

\section{Referências bibliográficas}

BRASIL. Senado Federal. Constituição Federal de 1988. Diário Oficial [da] República Federativa do Brasil, Poder Executivo, Brasília, DF, 1988.

CORPORAÇÃO FINANCEIRA INTERNACIONAL - IFC. Padrões de desempenho sobre sustentabilidade socioambiental. 2012. Disponivel em: <https://www.ifc.org/wps/wcm/connect/f2679b79-e082-4bc9ae04-e5dbee83791d/PS_Portuguese_2012_Full-Document.pdf?MOD=AJPERES\&CVID=jSD0tSw\#: :text $=\mathrm{A} \% 20 \mathrm{IFC} \% 20$ utiliza\%20a\%20Estrututa,aplicados\%20por\%20outras\%20institui\%C3\%A7\%C3\%B5es\%20 financeiras >. Acesso em: 20 mar. 2021.

DERROSSO, G.; ICHIKAWA, E. Y. O papel da Crabi no assentamento dos ribeirinhos atingidos pela construção da hidrelétrica de Salto Caxias no estado do Paraná. Revista de Administração Pública, Rio de Janeiro, v. 47, n. 1, p. 133-155, 2013.

FONSECA, B. C. et al. Análise do estudo de caso da comunidade rural de São Sebastião do Soberbo, atingida pela UHE Risoleta Neves, sob a perspectiva dos conflitos, das ideias e dos argumentos. Revista Geográfica Acadêmica, Paricarana, v. 9, n. 1, p. 116-129, 2015.

FUNDAÇÃO RENOVA. Os sete desafios do reassentamento. Revista dois Pontos, [S.l.], 2018. Disponível em: <https://revistadoispontos.org/materias/desafios-reassentamento/\#>. Acesso em: 19 set. 2019.

HAESBAERT, R. Da desterritorialização à multiterritorialidade. Boletim Gaúcho de Geografia, Porto Alegre, v. 29, n. 1, p. 11-24, 2003.

LOPES, B. S. et al. Complexo Portuário do Açu: Propostas para que a riqueza gerada possa retornar à comunidade de São João da Barra utilizando a ferramenta Accountability. Perspectivas Online: Exatas e engenharia, Campos dos Goytacazes, v. 1, n. 1, p. 23-46, 2011.

MEDEIROS, R. M. V.; LINDER, M. A terretorialização de assentados e reassentados no Rio Grande do Sul: os espaços de vida no contexto da luta pela terra. Revista FSA, Teresina, v. 11, n. 2, p. 234-246, 2014.

MERA, C. M. P. D. et al. Da serra/roça para o território campo/lavoura: transformações socioeconômicas e culturais de reassentados rurais atingidos por barragens. Revista NERA, Presidente Prudente, v. 21, n. 41, p. 62-84, 2018.

MESQUITA, Z. Do território à consciência territorial. In: BRANDÃO, C.; MESQUITA, Z. (Ed.). Territórios do Cotidiano uma introdução a novos olhares e experiências. Porto Alegre: Ed. UFRGS - Ed. UNISC, 1995 p. 76-92.

MMX. Porto do Açu - RJ: RIMA - Relatório de Impacto ao Meio Ambiente. Rio de Janeiro: CAL Consultoria Ambiental., 2006. 722 p.

ORGANIZAÇÃO DAS NAÇÕES UNIDAS - ONU. Declaração Universal dos Direitos Humanos. In: ASSEMBLÉIA GERAL DA ONU, 1948, Paris. Paris: ONU, 10 dez. 1948. Disponível em: <https://www. ohchr.org/EN/UDHR/Pages/Language.aspx?LangID=por>. Acesso em: 19 set. 2019.

PARENTE, T. G. (In)visibilidade de atores no processo de reassentamentos da Usina Hidrelétrica Luís Eduardo Magalhães, no Tocantins. Revista Territórios \& Fronteiras, Cuiabá, v. 8, n. 1, p. 149-164, 2015.

PIQUET, R. P.; SHIMODA, E. De braços abertos: as expectativas quanto aos impactos do Porto do Açu, Rio de Janeiro. Revista Política e Planejamento Regional, Rio de Janeiro, v. 1, n. 1, p. 121-137, 2014.

PORTO DO AÇU. Vila da Terra. Portal da Porto do Açu, 2017. Disponível em: < https://portodoacu.com. br/vila-da-terra/>. Acesso em: 11 nov. 2018.

PRADO, F; ROCHA, B. N. Territórios em Disputa: resistência e luta no processo de implantação do Complexo Industrial Superporto do Açu. Revista Política e Planejamento Regional, Rio de Janeiro, v. 2, n. 2, p. 329-349, 2015.

RIBEIRO, A. M.; ANDRADE, L. C.; MORET, A. S. Os Estabelecidos e os Outsiders da Amazônia: uma reflexão sociológica acerca de um projeto de reassentamento em Rondônia, Brasil. Revista Territórios \& Fronteiras, Cuiabá, v. 8, n. 2, p. 275-290, 2015.

RIO DE JANEIRO. Assembléia Legislativa do Estado do Rio de Janeiro. Decreto no 25455 de 28 de Junho de 1999. Rio de Janeiro, RJ. Disponível em: <http://alerjln1.alerj.rj.gov.br/decest.nsf/c8ea52144c8b5c 950325654c00612d63/59353eecd4d6b5e203256a65005c8595? OpenDocument\&Highlight=0,25455>. Acesso em: 15 out. 2019. 
RIO DE JANEIRO. Decreto no 41.915 de 19 de junho de 2009. Diário Oficial do Estado do Rio de Janeiro, Rio de Janeiro, RJ. Disponível em: <http://www.ioerj.com.br/portal/>. Acesso em: 20 out. 2019.

RIO DE JANEIRO. Tribunal de Contas do Estado do Rio de Janeiro. Estudos socioeconômicos dos municípios do Estado do Rio de Janeiro: São João da Barra. Rio de Janeiro, RJ, 2019. Disponível em: $<$ https://www.tce.rj.gov.br/web/guest/70>. Acesso em: 20 set. 2019.

ROQUETTI, D. R. et al. Deslocamento populacional forçado por grandes barragens e resiliência socioecológica: O caso da Usina Hidrelétrica de Barra Grande no sul do Brasil. Ambiente \& Sociedade, São Paulo, v. 20, n. 3, p. 117-138, 2017.

SANTOS, I. G.; SOUZA, P. B.; PREVIERO, C. A. Quintais agroflorestais na percepção dos moradores do reassentamento Mariana, Tocantins. Revista Verde de Agroecologia e Desenvolvimento Sustentável, Pombal, v. 11, n. 5, p. 95-102, 2016.

SANTOS, M. Espaço e método. São Paulo: Nobel, 1985. 88 p.

SANTOS, M. O dinheiro e o território. In: SANTOS, M. (Ed.). Território, territórios: ensaios sobre ordenamento territorial. 2. ed. Rio de Janeiro: DP\&A, 2006. p. 13-21.

SAQUET, M. A. Reterritorialização e identidade. In: MEDEIROS, R. M. V.; FALCADE, I. (Org.). Tradição versus tecnologia: as novas territorialidades do espaço agrário brasileiro. Porto Alegre: Editora da UFRGS, 2009.

SCOTT, P. Re-assentamento, Saúde e Insegurança em Itaparica: um modelo de vulnerabilidade em projetos de desenvolvimento. Saúde e Sociedade, São Paulo, v. 15, n. 3, p. 74-89, 2006.

SPOSITO, E. S. Geografia e Filosofia: contribuição para o ensino do pensamento. In: SPOSITO, E. S. (Ed.). Geografia e Filosofia: contribuição para o ensino do pensamento. São Paulo: Editora UNESP, 2004. 218 p.

TAN, Y.; YAO, F. Three Gorges Project: effects of resettlement on the environment in the reservoir area and countermeasures. Population and Environment, Providence, v. 27, n. 4, p. 351-371, 2006.

VILELA, W. A. et al. Determination of Potential Areas for Resettlement of Families Affected by the São Francisco River Integration Project Using Geotechnologies. BCG - Boletim de Ciências Geodésica, Curitiba, v. 23, n. 2, p. 338-351, 2017.

WILMSEN, B.; WEBBER, M.; DUAN, Y. Involuntary rural resettlement: resources, strategies, and outcomes at the Three Gorges Dam, China. Journal of Environment \& Development, Santa Barbara, v. 20, n. 4, p. 355-380, 2011.

SOBRE AS AUTORAS

Elaine Cristina Ribeiro Mendes Emerick. Programa de Pós-Graduação em Geografia da Universidade Federal Fluminense, em Campos dos Goytacazes (UFF/Campos). Graduada em Geografia e Pós-graduada em Educação Ambiental pelo Centro Universitário do Leste de Minas Gerais. Aluna do Programa de Pós-Graduação em Geografia da Universidade Federal Fluminense, em Campos dos Goytacazes (UFF/Campos).

Elzira Lúcia de Oliveira. Programa de Pós-Graduação em Geografia da Universidade Federal Fluminense, em Campos dos Goytacazes (UFF/ Campos). Mestre e doutora em Demografia pela Universidade Federal de Minas Gerais (UFMG). Graduada em Ciências Econômicas pela UFMG. Professora associada da Universidade Federal Fluminense (UFF). 